\title{
Rainwater harvesting systems for a high quality, supplementary water supply in Nepal
}

\author{
Jane Nichols \\ School of Engineering, Griffith University, Brisbane, Australia \\ janenichols90@gmail.com.au
}

\begin{abstract}
Although Nepal is rich in water resources, in 2011 it was estimated that water supply coverage across Nepal is only $80.4 \%$ of which only $17.9 \%$ of water supply systems are considered to be functioning well. Nepal Water for Health (NEWAH) is a Nepali non-government organisation that has implemented several rainwater harvesting systems (RWHS) in the rural hilly regions of Nepal. Hydrological modelling and analysis of NEWAH's RWHS allowed for the development of a strategy to improve the effectiveness of the systems. RWHS will always be limited in Nepal due to monsoonal rainfall patterns however this high quality water supply should be prioritised for cooking and drinking. Increasing catchment areas to at least $30 \mathrm{~m}^{2}$ instead of increasing tank volumes can efficiently increase the water supply. A literature review on the quality of harvested rainwater was completed, and recommendations were made for maintaining the high quality of water throughout collection, conveyance, storage and use. Monitoring and evaluation of installed systems is necessary and recommendations need to be further investigated and considered in Nepal where the social and cultural context can be fully understood. Appropriate use of this technology can provide a high quality supplementary water supply that can directly improve the health of consumers and provide those living in the hilly regions of Nepal with the foundations for further development.
\end{abstract}

KEYWORDS: water supply, rainwater harvesting systems, hydrological modelling, Gorkha district, hilly regions, Nepal.

\section{INTRODUCTION}

According to WHO-UNICEF 780 million people globally still live without access to an improved water supply (2014). The Nepali Department of Water Supply and Sewerage (DWSS) reported that of the $80.4 \%$ of the population that have access to a water supply system in their country, only $17.9 \%$ function well, $38.9 \%$ need minor repair, $11.8 \%$ need major repair, $21.0 \%$ need rehabilitation, $9.1 \%$ need reconstruction and $1.6 \%$ cannot be restored (DWSS, 2011). Nepal is suffering the effects of a recent civil war and ongoing political instability which continue to create challenges in the provision of a safe drinking water supply (Biggs et al, 2013). An improved water supply is defined as either a household connection, public standpipe, borehole, protected dug well, protected spring or rainwater collection that provides at least $20 \mathrm{~L} /$ person/day and is located within $1 \mathrm{~km}$ from the home (WHO-UNICEF, 2010). An improved water supply source not only directly improves the health of consumers; it also provides opportunities for growth and development in areas such as education, employment, gender equality and an overall improved quality of life.

Although Nepal has ample fresh water resources, there are several challenges associated with providing
Nepali people access to a safe drinking water supply, particularly citizens located in rural hilly areas, where $43 \%$ of the total population live (Government of Nepal, 2011). As stated by WHO-UNICEF, 93\% of Nepali people living in urban areas have access to an improved water supply compared with $88 \%$ of people in rural areas (WHO-UNICEF, 2014). These figures highlight the urban and rural disparities in Nepal, however these statistics may not consider the limited functionality of systems mentioned earlier.

A partnership between NEWAH and Engineers Without Borders Australia (EWB) has been formed to support NEWAH in the provision of water, sanitation and hygiene facilities for Nepali people. The second most popular water supply technology implemented by NEWAH is the ferro-cement, jar shaped RWHS with a volume of $4000 \mathrm{~L}$ or $6500 \mathrm{~L}$ (Figure 1). Although this technology is widely used, many systems do not provide a high quality water source, or fall into disrepair mainly due to a lack of maintenance and other issues. There has been limited investigation into the impact of NEWAH's installed systems on water quality and whether this is an effective water supply solution. Aspects associated with RWHS such as maintenance, tank size, first flush devices, material use and water quality were identified by NEWAH as requiring further investigation. 


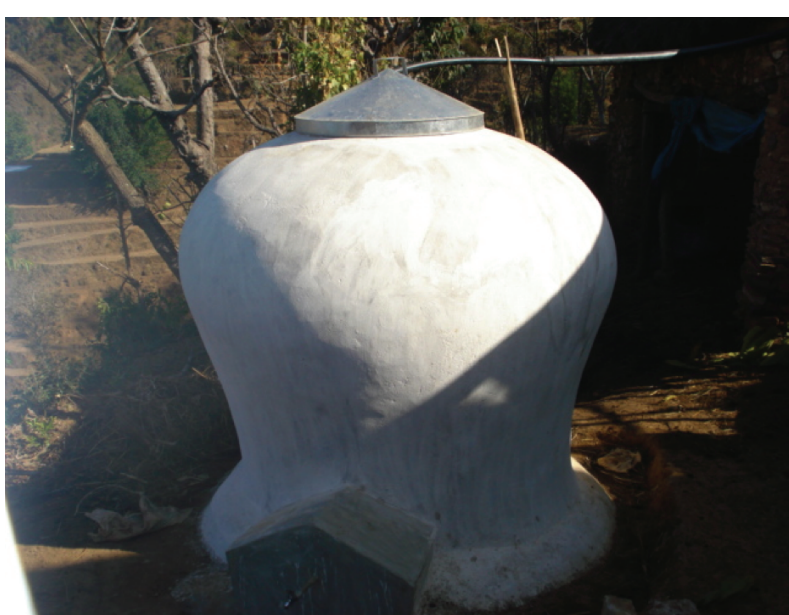

Figure 1: $\quad 6500$ L RWHS installed by NEWAH.

Through the completion of hydrological modelling and a water quality analysis of NEWAH's existing RWHS, modifications and improvements could be made. This project focused on the community of Mathillo Semrang, Gorkha District which is a typical community, representative of many others isolated in the hilly regions of Nepal without access to a quality water supply. Materials availability, socio-economic and meteorological information was obtained based on Mathillo Semrang to determine realistic inputs for modelling and analysis.

One of the greatest benefits of implementing RWHS for families located in rural hilly regions of Nepal is having access to a potable water supply at the house. Women and children usually hold the major responsibility for collecting water for the entire family. The tradition of girls and women collecting water for their families continuously enforces the inequalities women face with access to education and employment (United Nations Development Programme, 2006). Time saved from collecting water allows children to attend school more frequently and increases time and energy women have to rest or take up extra incoming generating activities. A readily available water supply at the house can also reduce water-borne diseases such as diarrhoea and gastroenteritis through the increases in sanitation and hygiene practices.

Rainfall in Nepal is dominated by monsoonal weather patterns, inter-annual variations and climate change, which all affect the reliability of RWHS (Romilly \& Singh, 2009; Devkota \& Quadir, 2006). This distinct wet and dry season greatly impacts upon the amount of water that can be supplied from a RWHS. Another limitation in providing water supply solutions to communities located in the rural hilly regions is access to the site. Ferro-cement tanks are logistically the easiest option as materials can be carried up the mountain by porters, and tanks constructed on site.

Although many Nepali people prefer to use flowing water sources for drinking and cooking, Domenech et al. (2012) states that $85 \%$ of surveyed families with
RWHS use this source to meet their cooking and drinking needs. It was suggested that the remaining $15 \%$ did not consume rainwater due to social conventions and traditional beliefs that support the idea of still water being impure (Domenech et al, 2012). This emphasises the importance of education so Nepali people can understand the water quality of different sources and be able to make informed decisions on water supply for their family. Education and capacity building to ensure proper operation and maintenance of RWHS proves to be the most critical factor attributing to the successful adoption of this technology. Education of families upon implementation of RWHS is essential, however, children also need to be educated on water, sanitation and hygiene in schools to create long lasting changes in society.

The cost of a RWHS is one of the major disadvantages when compared with other water supply options which may cause this technology to be overlooked. RWHS are twice as expensive compared to gravity flow schemes which are more commonly implemented in the rural hilly regions. Although RWHS are more expensive than gravity flow schemes, providing water supply to the remaining $20 \%$ of the unserved population will require more expensive alternative technologies to provide services in isolated and challenging environments.

Capacity building of local technicians in rural villages in Nepal can initiate involvement from the private sector in RWHS construction, eventually increase the uptake of this technology, and increase the opportunities Nepali people have in accessing a safe drinking water supply. Private sector involvement is recommended from an extensive survey on RWHS in Nepal and was proven successful in Thailand with the Thai Jar Project (Domenech et al, 2012).

\section{METHODS}

\subsection{Hydrological analysis}

The hydrological analysis was completed by modelling various RWHS in the program RainTank (Jenkins, 2007). The analysis was completed based on rainfall in the Gorkha District and demand data from Mathillo Semrang that is representative of other communities in remote hilly regions of Nepal.

The demand was calculated based on demand information and design period recommended by NEWAH and population growth rates and people per household from the Central Bureau of Statistics (2011). Two standard NEWAH RWH tank volumes (4000 L and $6500 \mathrm{~L})$, varying roof catchment areas, cooking and drinking demand of $70 \mathrm{~L} /$ household/ day and total demand of $315 \mathrm{~L} /$ household/day were used to model different situations. The demands were calculated based on a 15 year design period, $1.92 \%$ population growth rate and 5.25 people/ 
household in accordance with NEWAH's standard design process.

The total annual rainfall for Gorkha District was sourced from the Environment Statistics of Nepal 2008 report produced by the Central Bureau of Statistics and the Department of Hydrology and Meteorology Nepal (Central Bureau of Statistics, 2008; Department of Hydrology and Meteorology, 2002). The monthly rainfall distributions of Nepal reported by Practical Action were used to allocate percentages of total annual rainfall to each month (Practical Action Nepal, 2009). The number of rainy days at various intensities was recorded for two years in the data set provided by the Department of Meteorology and Hydrology. Using this data, a daily distribution for each month was determined by converting the number of rainy days at different rainfall intensities to percentages of the total monthly rainfall, and allocating them to randomly generated days of the month. This provided a daily rainfall data set for Gorkha district from 1996 until 2006 suitable for use in the RainTank program.

\subsection{Water quality analysis}

The WHO (2008) states that harvested rainwater generally has less pathogens than unprotected surface water. Harvested rainwater can generally be assumed as a higher quality source as a certain amount of quality control is possible through appropriate design, operation and maintenance. As water quality tests have not been conducted on RWHS implemented by NEWAH, the investigation in this research was limited to the information collated through discussions with EWB and NEWAH staff, feedback from communities with RWHS and published research in this area. The analysis investigated the quality of rainwater and focused on design features to ensure that capture, diversion, storage and abstraction can occur without degrading the quality of the rainwater.

\section{$3 \quad$ RESULTS}

\section{Hydrological analysis}

The major limiting factors of RWHS in Nepal are the small household catchment areas and monsoonal rainfall patterns. Figure 2 indicates that RWHS only satisfies $17 \%$ of an average household's total demand with an average catchment area of $15 \mathrm{~m}^{2}$, (observed in Mathillo Semrang), using either a $4000 \mathrm{~L}$ or $6500 \mathrm{~L}$ storage tank in an average rainfall year of $1574 \mathrm{~mm}$.

Some consumers in Nepal have suggested that this could be overcome by increasing the tank size or procuring a second tank. This may have initiated from having seen the $4000 \mathrm{~L}$ or $6500 \mathrm{~L}$ tanks overflow during the wettest time of the year, or from a misconception that if they have a larger sized tank they will collect more water. Even though tanks may overflow during the wet season, the suggestion of increasing the storage volume will increase the costs dramatically whilst only providing a slightly improved demand satisfaction. Figure 3 clearly highlights the small improvement increasing the storage volume has on the demand satisfied, compared to the significant gains achieved by

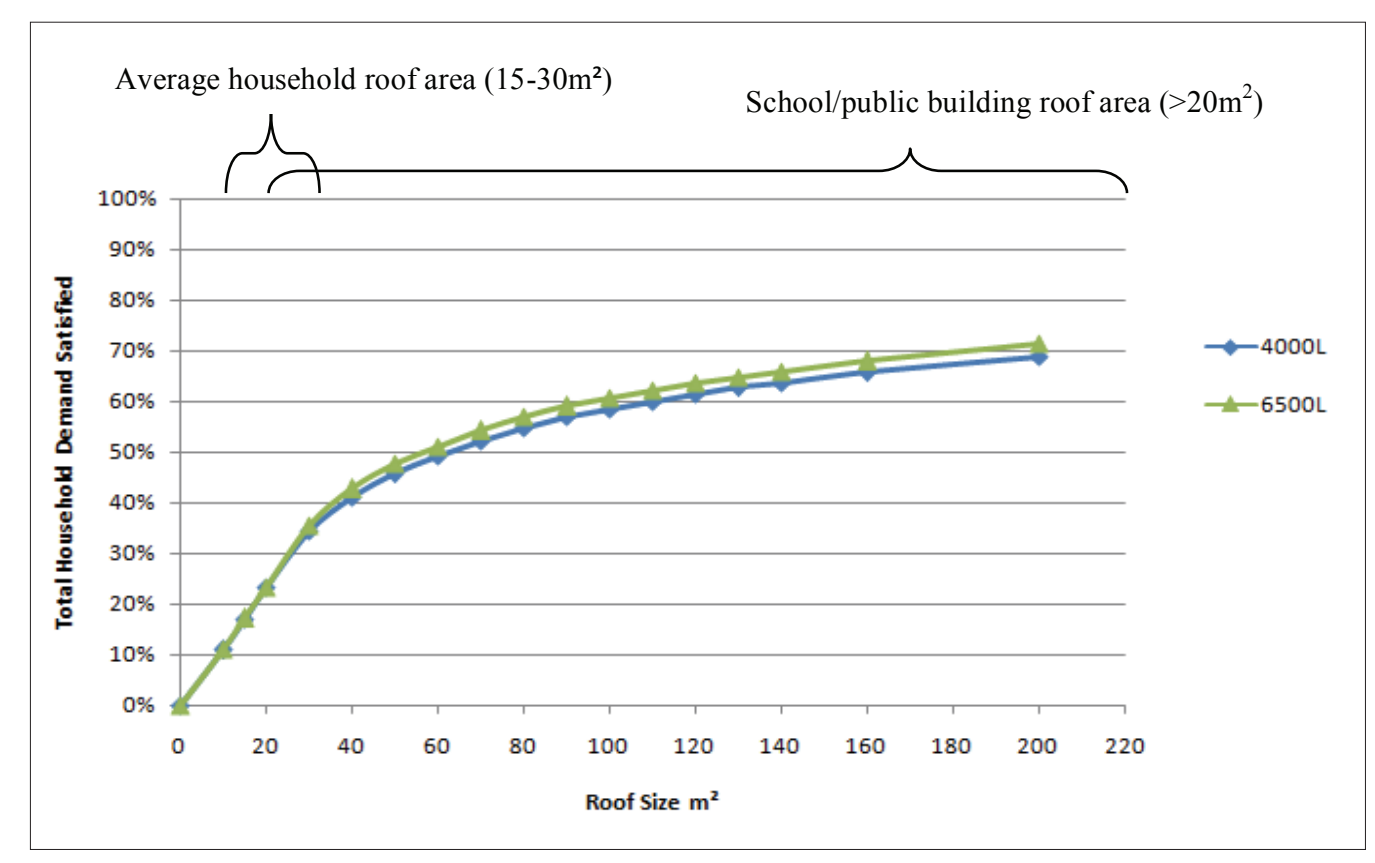

Figure 2: Total demand satisfied in an average rainfall year with

NEWAH's standard tank volumes. 
increasing the catchment area. The implementation of RWHS for public buildings such as schools and health posts would be more effective than household systems due to the larger catchment areas. An appropriate tank size for public buildings would vary depending on the size of the catchment area, local rainfall and economic resources.

Implementing a $6500 \mathrm{~L}$ storage tank is preferable over the $4000 \mathrm{~L}$ model so that households can be prepared for the possible impacts climate change might have on the current rainfall distributions and intensities. As the major limiting factor for average households is the roof size, increasing the catchment area to approximately $30 \mathrm{~m}^{2}$ is strongly recommended to improve the effectiveness of RWHS. In an average rainfall year with a $6500 \mathrm{~L}$ tank and catchment area of at least $30 \mathrm{~m}^{2}$ approximately $85 \%$ of a household's cooking and drinking demand can be satisfied (Figure 4). Increasing the roof area instead of increasing the storage volume would be more economically feasible in most situations, especially when recycled, local materials are used.

It is evident that the RWHS can provide all the water needed for cooking and drinking from June until December, however can only satisfy $33 \%$ in February and 23\% in March (Figure 5). The large volumes of water from the monsoon period between June and September can almost supply the total cooking and drinking demand for October, November, December and January. Between June and September the RWHS can be used for non-potable demands; however, around September rainwater should be prioritised for cooking and drinking only.

Residents who are currently using RWHS implemented by NEWAH state they have seen the tanks overflow and that the tank remains dry for approximately four months of the year. As daily rainfall was extrapolated from annual rainfall data, the daily distributions may not be accurate. The days

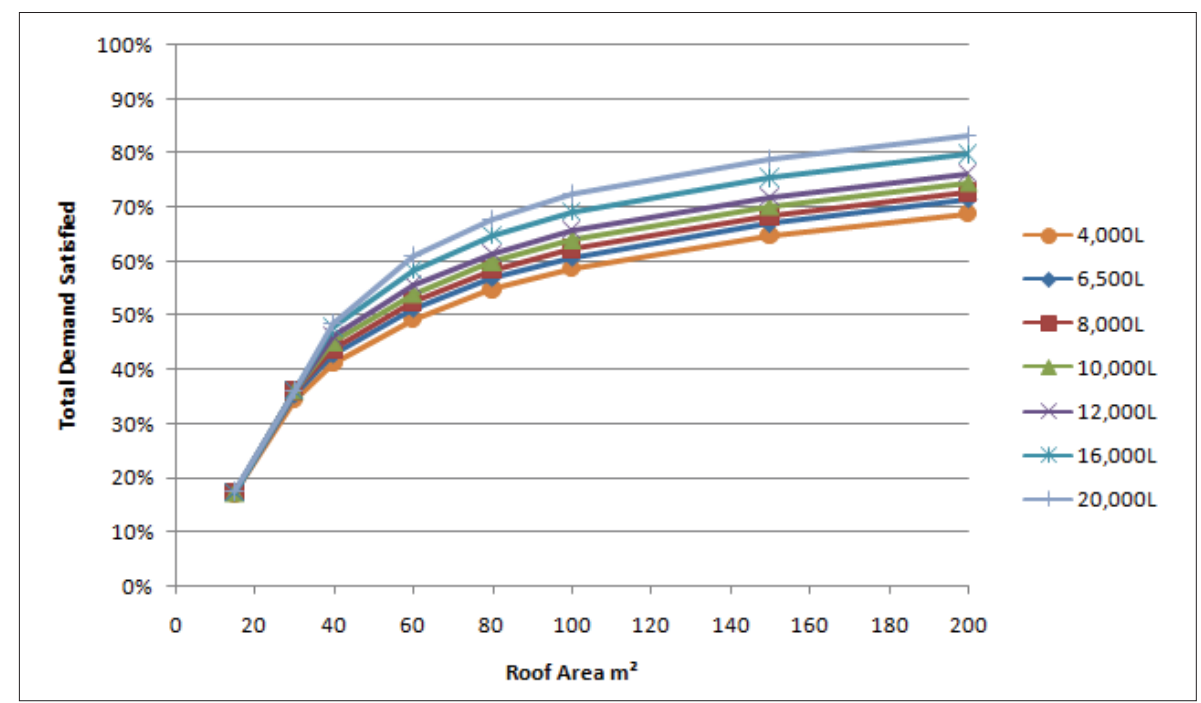

Figure 3: Effect of tank volume on total demand satisfied.

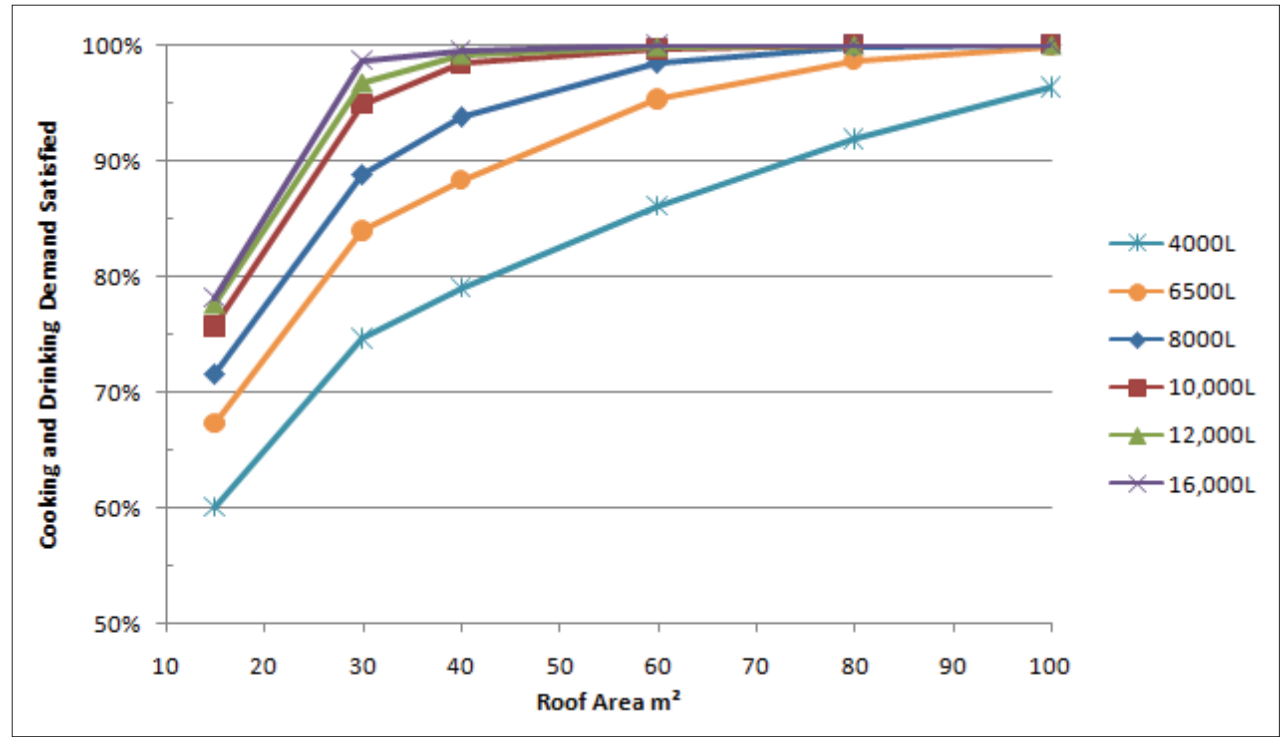

Figure 4: Effect of tank volume on cooking and drinking demand satisfied. 


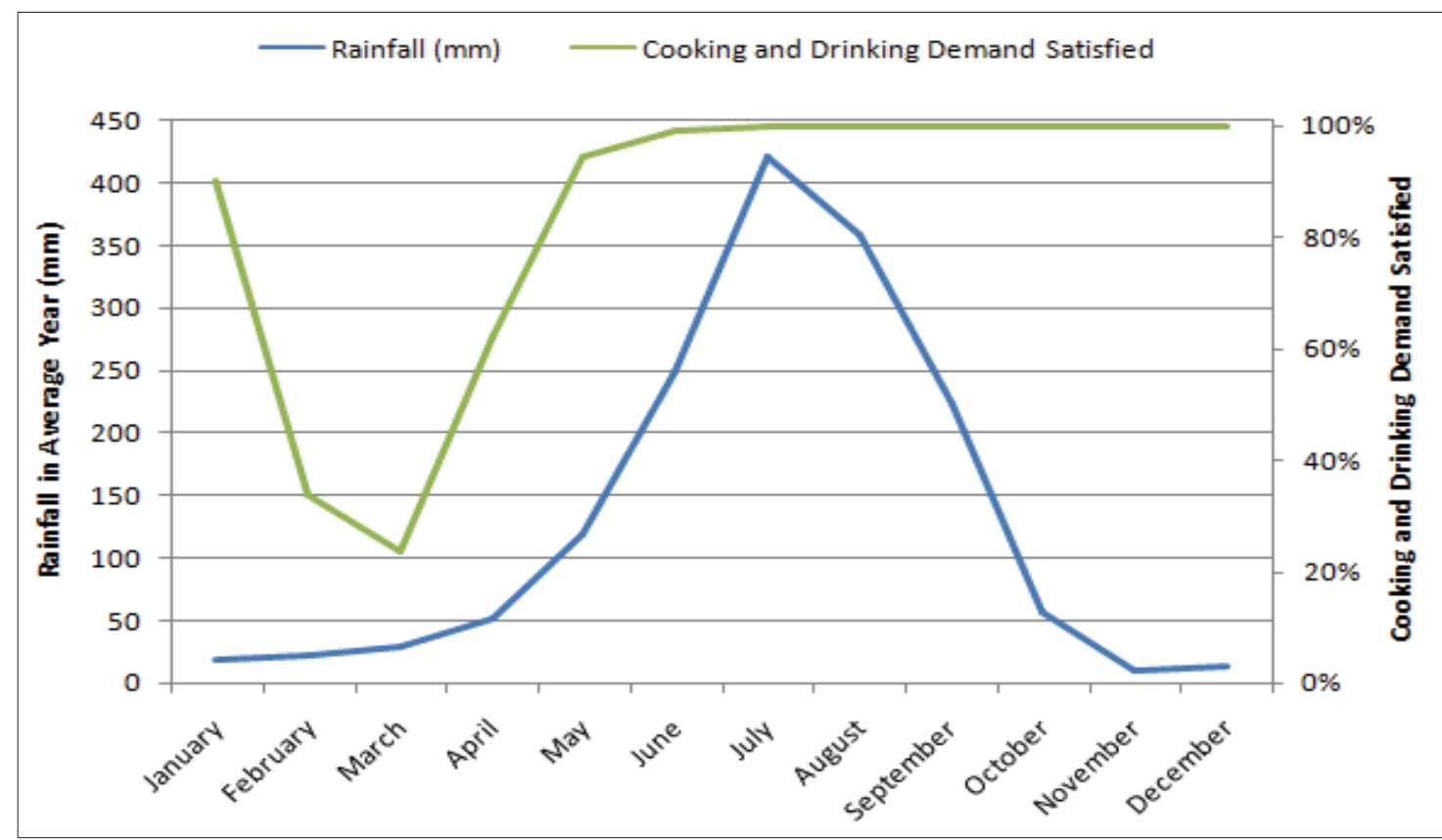

Figure 5: Monthly distributions of rainfall compared with cooking and drinking demand satisfied (6500 L storage volume and $30 \mathrm{~m}^{2}$ catchment area).

when rainfall occured was randomly generated which may not show when tanks overflow due to extended rainfall events. This highlights the limitations of the modelling and available data resulting in a difference between the results and reality.

\subsection{Water quality analysis}

There are many case studies that state RWHS can provide a high quality water supply source ensuring the system is correctly designed, operated and maintained (Waller, 1989; Sazakli et al, 2007; Domenech et al, 2012). In a study conducted on atmospheric contamination of RWHS, it was found that the major contributors are traffic and industry (Gardner et al, 2009). It was therefore assumed that RWHS in the rural hilly regions of Nepal are not usually at risk from atmospheric contamination of the water. Other chemical contaminants from the catchment area not considered an issue for this RWHS in the rural hilly regions of Nepal as long as lead based paints are not used on corrugated iron roofing for the catchment area.

Physical parameters such as turbidity, temperature, colour, taste, and odour are likely to result in complaints from consumers (WHO, 1996). In Nepal, this may result in the use of alternative unprotected or untreated water sources such as surface water for cooking and drinking. Turbidity of the harvested rainwater can usually be decreased through the occurrence of natural sedimentation effects inside the storage tank. Regular maintenance and cleaning of the catchment area will also assist in improving the colour, taste and turbidity of the water. The microbiological parameters of rainwater harvesting are of most concern in the rural hilly regions of Nepal as pathogenic microorganisms can enter a RWHS through various pathways and can result in serious acute health effects for the consumers (Lye, 2009). Figure 6 shows the relationship between elements of the RWHS, the main contamination pathways and the possible key barriers that can be implemented in the system to reduce contamination. This risk-based approach identified some key areas for improvement to protect the water quality of RWHS in Nepal. The catchment area needs to be cleaned after periods with no rainfall, and sediment should be removed from the system if there is significant build-up before the next rainfall event or start of monsoon season. Water Safety Plans should be developed by families with the support of NGO and government staff, to allow families to be involved in the identification of hazards in a RWHS, assessment of risks, developing control measures and monitoring the system (Barrington et al, 2013). This allows the consumers to understand the direct relationships between tank maintenance, water quality and health whilst further engaging the family and increasing their feeling of ownership and empowerment.

A study conducted by Gardner et al. (2004) did not identify a consistent reduction in contaminants by use of the first flush, whilst many studies acknowledge first flush diverters as an essential design requirement for significantly improving harvested rainwater quality (Yaziz et al, 1989; Abbott et al, 2006; Kinkade-Levario, 2007). A first flush device that operates automatically and captures the lower quality water for reuse on kitchen gardens and 


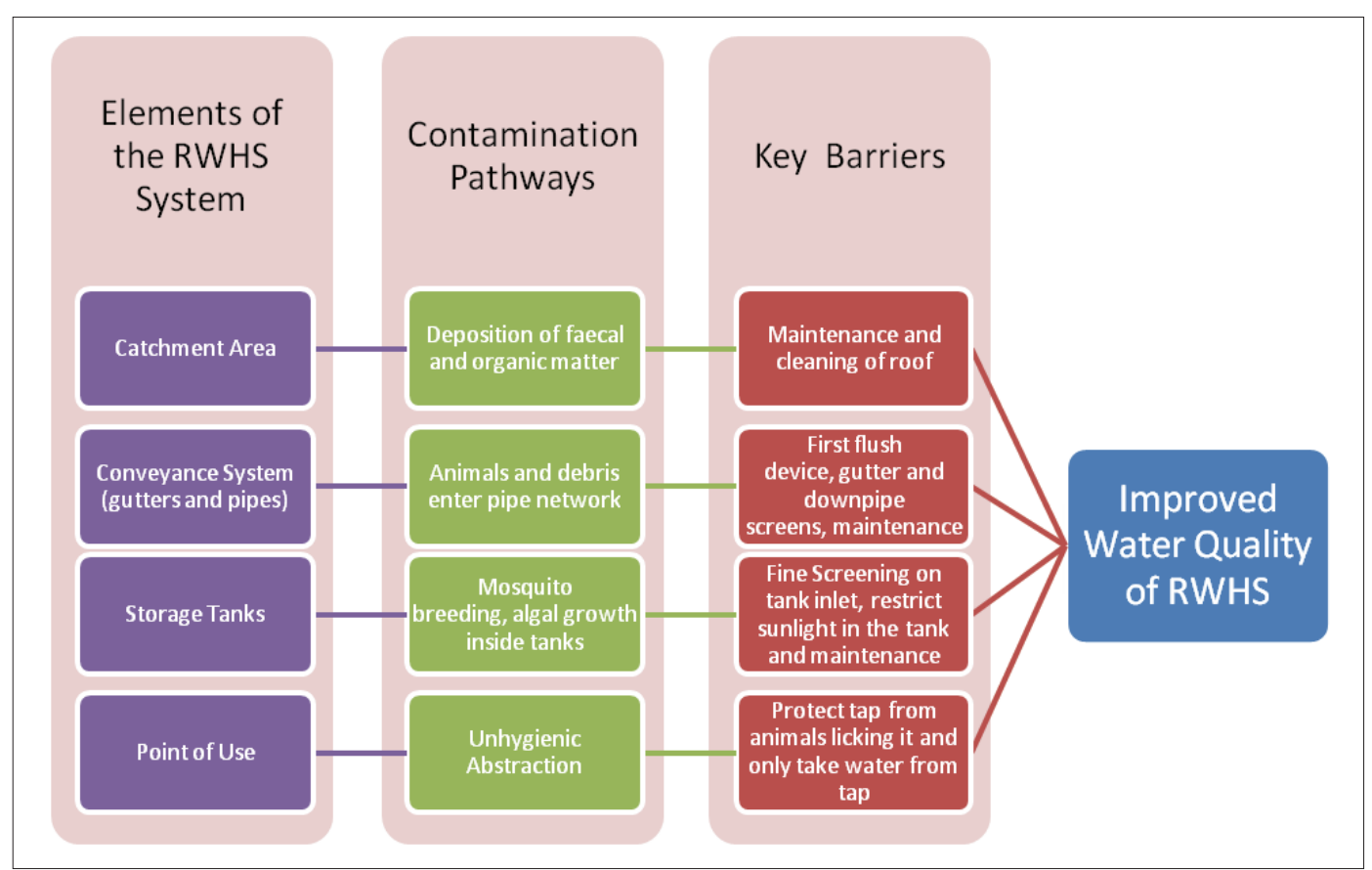

Figure 6: Key barriers for water quality.

other non-potable demands is highly recommended to ensure first flushes are operated before and after monsoon season when water is scarce. Self-cleaning screens on downpipes can reduce the amount of debris entering the pipe system and reduce the amount of maintenance needed on the fine screen at the tank inlet. Animals licking taps can also cause contamination of water in the tank; therefore a cover on the tap is required (Visvanathan, 2006).

\section{STRATEGY AND RECOMMENDATIONS}

An overview of the issues surrounding the adoption of RWHS in Nepal as well as the hydrological and water quality analysis have led to the development of modifications and recommendations for NEWAH and other Nepali organisations working in water supply to consider. Further community consultation is also required to ensure modifications will be accepted by communities and piloting of modifications to a small sample of RWHS may be beneficial to determine whether it will be successful. This strategy is summarised into four key areas for improvement; quality, quantity education and monitoring and evaluation (Figure 7). The quality and quantity of rainwater can be improved through the implementation of key barriers and increasing the roof size instead of increasing the tank volume. Some major issues affecting the success of RWHS such as maintenance and cultural acceptance of rainwater for cooking and drinking can be improved through education. Developing a Water Safety Plan with families and implementing RWHS in schools will facilitate education of this water supply option. It is also recommended to adapt the project evaluation manual used by Rainwater Cambodia to identify unknown issues with NEWAH's design and to assist in promoting the benefits of this technology (Scott, 2011).

\section{CONCLUSIONS}

Although Nepal is abundant in water resources, the provision of water supply is challenging, particularly in the rural, hilly regions. RWHS is a commonly implemented appropriate water supply technology particularly useful for those living in areas where access is difficult. RWHS can provide a high quality water supply for cooking and drinking ensuring the appropriate design, operation and maintenance.

To control the quality of RWHS in Nepal it is recommended to install an automatic first flush device that captures the lower quality water, improve maintenance of systems, incorporating a cover over the abstraction tap and installing self-cleaning screens on downpipes. The most effective way to improve the quantity of water supplied is to increase catchment areas to at least $30 \mathrm{~m}^{2}$ instead of increasing tank volumes. The water supplied from RWHS will always be limited by the monsoonal rainfall periods, however the harvested rainwater can provide a high quality supply, prioritised for cooking and drinking. Education as well as monitoring and evaluation also need to be improved to ensure systems are properly operated and maintained and all issues and benefits of RWHS are known.

Although RWHS is ineffective in meeting the total demand of a household, ensuring the strategy is considered, this technology can provide a high 


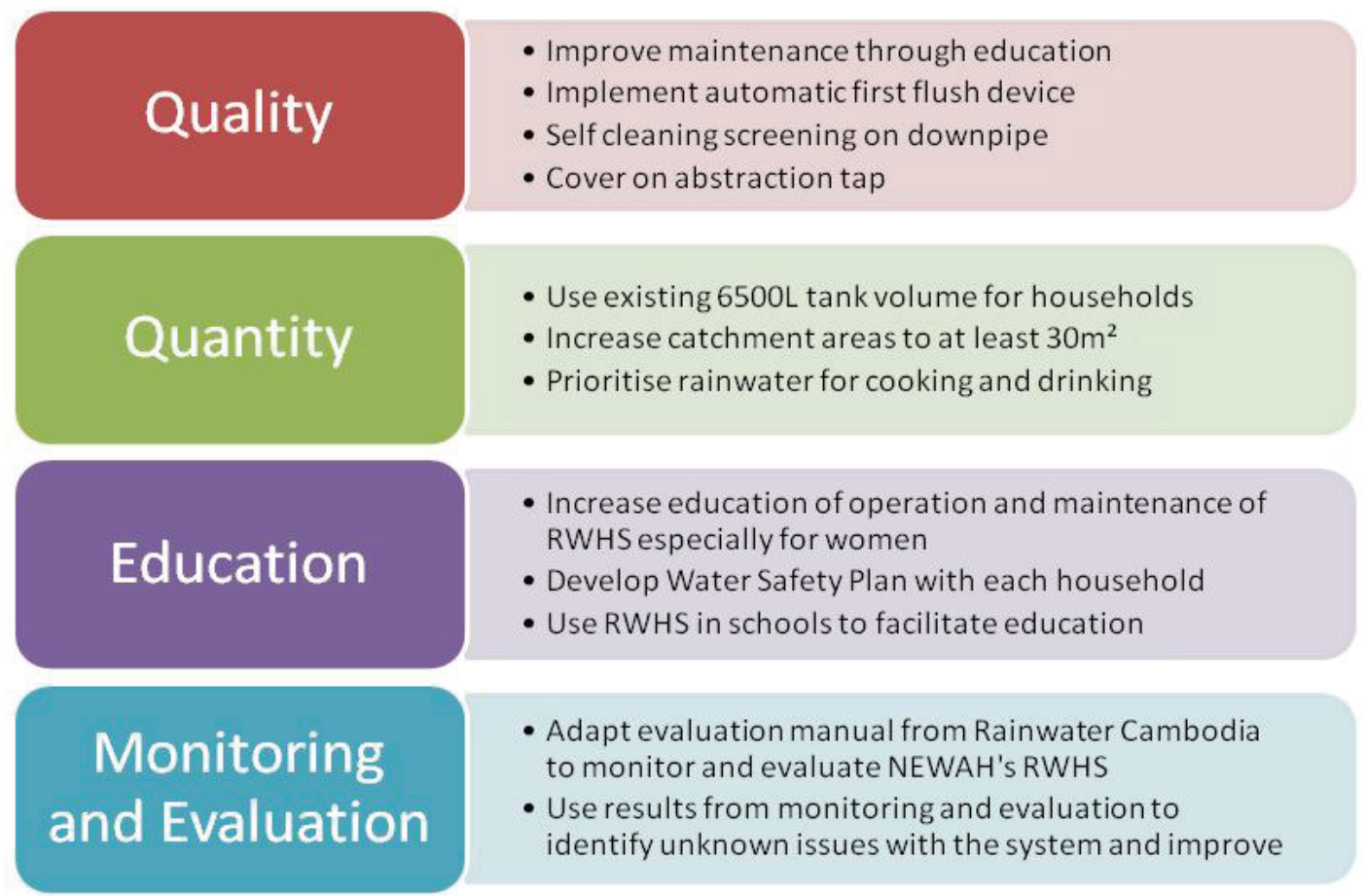

Figure 7: Strategy for NEWAH's RWHS.

quality, supplementary water supply to improve the quality of life for Nepali people in the rural hilly regions.

\section{ACKNOWLEDGEMENTS}

Many thanks to Dani Barrington, Nepal Water for Health, Engineers Without Borders, Graham Jenkins and Ian Cameron who provided assistance throughout this project.

\section{REFERENCES}

Abbott, S. E., Douwes, J. E. \& Caughley, B. P., 2006, 'A survey of the microbiological quality of roof-collected rainwater of private dwellings in New Zealand'. New Zealand Journal of Environmental Health, vol. 29, pp. 6-16.

Barrington, D., Fuller, K. \& McMillan, A., 2013, 'Water safety planning: adapting the existing approach to community-managed systems in rural Nepal', Journal of Water, Sanitation and Hygiene for Development, vol. 3, no. 3, pp. 392-401.

Biggs, E. M., Duncan, J. M., Atkinson, P. M. \& Dash, J., 2013, 'Plenty of water, not enough strategy, How inadequate accessibility, poor governance and a volatile government can tip the balance against ensuring water security: The case of Nepal', Environmental Science and Policy, vol. 33, pp. 338-394.

Central Bureau of Statistics, 2008, Environment Statistics of Nepal 2008, Thapathali, Kathmandu, Nepal.
Central Bureau of Statistics, 2011, National Population and Housing Census, viewed 13 March 2013, <http:// census.gov.np/>.

Department of Hydrology and Meterology, 2002, Climatological Records of Nepal 1999-2000, Department of Hydrology and Meterology, Kathmandu, Nepal.

Department of Hydrology and Meterology, 2014, Climate Data Portal: Results for Gorkha Station, viewed 20 June 2013, <http://www.dhm.gov.np/dpc/>.

Department of Water Supply and Sewerage National Management Information Project, 2011, Final Report of Nationwide Coverage and Functionality Status of Water Supply and Sanitation in Nepal, Kathmandu, Nepal.

Devkota, L. P. \& Quadir, D. A., 2006, Long Range Forecasting (LRF) of Monsoonal Rainfal in Nepal. Dhaka, Bangladesh.

Domenech, L., Heijnen, H. \& Sauri, D., 2012, 'Rainwater harvesting for human consumption and livelihood improvement in rural Nepal: benefits and risks'. Water and Environmental Journal, vol. 26, no. 4 , pp. 1-8.

Gardner, T., Huston, R., Chan, Y. C., Shaw, G. \& Chapman, H., 2009, 'Characterisation of Atmospheric Deposition as a source of contaminants in urban rainwater tanks', Water Research, vol. 43, no. 6, pp. 1630-1640.

Government of Nepal, 2011, Sector Status Report May 2011 in Ministry of Physical Planning and Works, Kathmandu, Nepal.

Jenkins, G., 2007, 'Use of continuous simulation 
for the selection of an appropriate urban rainwater tank'. Australian Journal of Water Resources, vol. 11, no. 2, 231-245.

Kinkade-Levario, H., 2007, Design for Water-Rainwater Harvesting, Stormwater Catchment, and Alternate Water Reuse, Canada, New Society Publishers.

Lye, D. J., 2009, 'Rooftop runoff as a source of contamination: A review'. Science of the Total Environment, vol. 407, no. 21, pp. 5429-5434.

Practical Action Nepal, 2009, Temporal and Spatial Variability of Climate Change over Nepal (1976 - 2005), Kathmandu.

Romilly, G. D. B. \& Singh, P. V., 2009, Nepal Climate Change Assessment, Asian Development Bank (ADB), Phillipines.

Sazakli, E., Alexopoulos, A. \& Leotsinidis, M., 2007, 'Rainwater harvesting, quality assessment and utilization in Kefalonia Island, Greece'. Water Research, vol. 41, no. 9, pp. 2039-2047.

Scott, K., 2011, A simple guide for Project Evaluation for Rainwater Cambodia, Melbourne, Australia.

United Nations Development Programme, 2006, Human Development Report 2006 - Beyond Scarcity: Power, Poverty and the Global Water Crisis, New York.
Visvanathan, C., Kandasamy, J. \& Vigneswaran, S., 2006, 'Rainwater Collection and Storage in Thailand: Design, Practices and Operational Issues', paper presented to RWHM Workshop, IWA $5^{\text {th }}$ World Water Congress and Exhibition, Beijing, China.

Waller, D. H., 1989, 'Rain Water - An Alternative Source in Developing and Developed Countries'. Water International, vol. 14, pp. 27-36.

WHO, 1996, Guidelines for Drinking-water quality, second editions, Health Criteria and other supporting information, volume 2. Geneva.

WHO, 2008, Guidelines for drinking-water quality (incorporating 1st and 2nd addenda, Vol.1, Recommendations. - 3rd ed), Geneva.

WHO-UNICEF, 2010, Definitions: Types of Drinking Water Sources and Sanitation, viewed 8 March 2012, <http://www.wssinfo.org/definitions-methods/ watsan-categories $>$.

WHO-UNICEF, 2014, Joint Monitoring Programme for Water Supply and Sanitation 2012. Progress on Sanitation and Drinking Water 2012 Update.

Yaziz, M. I., Gunting, H., Sapari, N. \& Ghazali, A. W, 1989, 'Variations in Rainwater Quality from Roof Catchments', Water Research, vol. 23, no. 6, pp. 761-765. 